in castrated males than in females. In barrows, more restricted than gilts (16 vs 7 p. 100), the lower feed efficiency was associated with a lower growth rate. Feed restriction slightly increased the feed conversion ratio in both sexes $(2.91$ vs $2.83, \mathrm{P}<0.05)$.

At slaughter (101 $\mathrm{kg} \mathrm{LW})$ the earlier feed restriction $\left(\mathrm{A}_{1}\right)$ resulted in an increase in muscle weight $(+1.45$ p. $100, P<0.10)$ and a decrease in the weight of fatty tissues in the half carcass $(-3.2$ p. $100, P<0.10)$ regardless of the sex. The later feed restriction was much more efficient in promoting the muscle development $(-5.4$ p. 100 vs +1.3 p. 100) at the expense of the fatty tissue (-11.7 p. 100 vs -3.5 p. 100) in castrated males than in females.

These experimental data do not substantiate the economic advantage of a feed restriction in growing-finishing gilts. In contrast, by improving feed efficiency in addition to carcass quality, the early feed restriction technique might be more attractive in females than in castrated males.

\title{
Compared utilization of wheat, maize and barley by pregnant sows
}

\author{
M. ETIENNE \\ I.N.R.A., Station de Recherches sur l'Elevage des Porcs, \\ Saint-Gilles, 35590 L'Hermitage
}

An experiment was carried out on 46 Large $W^{\prime} h i t e$ gilts in order to measure energy value and protein utilization of the main cereals during pregnancy. Animals were divided into four groups, each of them receiving the same diet during two successive pregnancies. Animals in the control group were fed a diet containing 86 p. 100 barley and 10 p. 100 soyabean oil meal. In the other three groups, diets contained 96 p. 100 barley, wheat or maize without supplementary protein. Feeding levels were the same during the two pregnancies, between 2.2 and $2.35 \mathrm{~kg} /$ day according to the diet in order to supply a similar amount of digestible energy to all females (around $7 \mathrm{Mcal} /$ day). A control diet was supplied to all animals during three-week lactations at the maximum level of $5 \mathrm{~kg} / \mathrm{day}$ during the first cycle and $5.2 \mathrm{~kg} /$ day during the second one. First mating occurred at a mean age of 229 days and a mean weight of $119 \mathrm{~kg}$. Animals were maintained in metabolism crates during early and late pregnancy and total urine and faeces were collected during 5-day periods and subsequently analysed.

No significant difference was observed between first and second pregnancy for all criteria concerned and results were pooled for the two pregnancies. Apparent digestibilities of dry matter and energy increased when the crude fibre content of the diet decreased $(81.4,79.1,87.2$ and 88.6 p. 100 for apparent digestibility of energy in the control, barley, wheat and maize groups, respectively). Digestibility of nitrogen followed similar variations, except in the maize group where the proportion of endogenous nitrogen in total faecal nitrogen was relatively high. In all cases, digestibilities were significantly higher at the beginning than at the end of pregnancy. Consequently, energy values of the diets decreased by 1.1 to 1.6 p. 100 between 39 and 94 days of pregnancy. Digestible energy contents of cereals measured in the present experiment were similar to values obtained with growing pigs : 3410,3790 and $3920 \mathrm{Kcal} \mathrm{DE} / \mathrm{kg}$ dry matter for barley with $6.1 \mathrm{p} .100$ crude fibre, wheat and maize, respectively. Energy apparent digestibility of diets with a low or medium crude fibre level was not improved in older and heavier pigs.

Nitrogen retention was about $11 \mathrm{~g} /$ day with diets containing $6 \mathrm{p} .100$ cereals and significantly lower than with the control diet $(15.9 \mathrm{~g} /$ day $)$. Only females in the control group had an improved nitrogen retention when pregnancy advanced, because of a lower urinary nitrogen excretion. Thus pregnant gilts and sows need diets with well balanced proteins, especially regarding the lysine content, to obtain a protein anabolism specific to gestation. 